\title{
PUTTING THEORY INTO PRACTICE: GAMIFICATION FOR STUDENT ENGAGEMENT
}

\author{
C. Garden, E.S. Rivera, \\ Edinburgh Napier University (UNITED KINGDOM) \\ errolscott.rivera@napier.ac.uk, c.garden@napier.ac.uk
}

\begin{abstract}
Gamification is the use of game design elements in a non-game contexts [1]. It is an intervention that has been used in a business setting for a number of years and is now becoming more and more applied in higher education [2]. We present the practical implications of our Gamification for Student Engagement framework developed for Higher Education.
\end{abstract}

Landers [3] suggests that gamification is the process of identifying, extracting, and embedding game attributes into learning, in order to affect the behaviours and attitudes that support the achievement of learning outcomes. His theory describes how this works in a successfully gamified learning situation. By employing gamification, the relationship between instructional content and the achievement of learning outcomes becomes explicit and can be altered in specific ways to affect student attitudes and behaviours oriented towards a particular learning goal. In addition to this, Bedwell's taxonomy of game attributes [4] makes it theoretically possible to narrow down the game attributes that have an evidence base for supporting any given learning outcome.

Student engagement can be explained using learning theories (e.g. see [5]). This framework can be used to understand player engagement and open up the door for learning theories to explain the effect of game attributes on players and thus on students. This allows us to define the aspects and functions of the behaviours/attitudes concept that underpins the theory of gamified learning. Now that the behaviour/attitudes that can be affected by gamification are better defined, we can start to consider exactly what gamification is affecting in engagement, how this happens, and what to look for to see if its works. This allows us to fill in the blanks between learning outcome and instructional content.

Building on the work of Landers, Bedwell and Kahu we will explore ways in which our new consolidated framework of Gamification for Student Engagement may be used in practice

Keywords: Gamification, Engagement, Theory, Practice, Pedagogy, Higher Education, constructivism.

\section{INTRODUCTION}

At Edinburgh Napier University in the United Kingdom (UK), we practice constructive alignment: designing curricula that link what students do to learn to intended learning outcomes using appropriate learning activities [6]. To help with this we adopted elements of the Transforming the Experience of Students through Assessment (TESTA) methodology [7]. TESTA aims to improve the quality of student learning through addressing programme-level assessment, so it is an assessment for learning tool. This tool aids exploration of the student experience of assessment, informing changes to assessment practice with the goal of improving that experience, and has been adopted by at least 40 universities in the UK, as well as in three other countries, and used on over 100 programmes [7]. Research surrounding TESTA has shown that assessments can be measured in isolation from the rest of the student experience whilst still being indicative of it, and suggests that formative assessments offer optimal conditions for a positive student experience [7]. Unfortunately, though, effective design of formative assessment is problematic. For example, we know that formative assessment facilitates student learning better when it does not focus on performance goals such as marks and grades [8], but when formative assessments are ungraded students consider them optional, so they do not to their best work or even participate [7]. Even when marks are offered, students have been shown to disregard accompanying comments intended to promote learning altogether [9].

The paradox of engagement with formative assessment begins in the pedagogic research that informs formative assessment practice across the UK, which fosters the cognitive acts of learning, as well as self-attribution and readiness to learn, informed by psychology and to a certain extent sociology [10]. This constructivist approach identifies that these aspects of feedback are the lecturers' key to 
understanding what the student needs in order to enable their own movement into a more advanced stage of learnedness, often referred to as the proximal zone of development [11]. The psychological, social, and behavioural aspects of this are consistent with engagement as defined by Kahu [5]. This means that formative assessment does not by default result in engagement, but is vulnerable to it. Whilst participation in formative assessment relies on a student's engagement, the utility of subsequent formative feedback relies on the lecturer's ability to not simply deliver useful feedback, but to do everything in their power to enable the student to engage with their feedback - that is to want to, to know how to, and to use the feedback [12]. However, the concept of student engagement suffers from poor definition, making it vulnerable to multiple interpretations: Kahu identifies multiple instances in engagement research, where the state of engagement is conflated with the causes or effects of engagement. They consolidated four major approaches to engagement into a framework in three parts wherein the antecedents to engagement such as culture, discipline, relationships with staff, curriculum and assessment all shape the state of engagement. The state of engagement comprises cognitive, behavioural, and emotional variables such as time on task, enthusiasm, and understanding, ultimately shaping the consequences of engagement, such as learning, achievement, life-long learning, and active citizenship [5]. Kahu proposes that engagement is circular, where increased engagement leads to increased outcomes of engagement such as academic performance, and in turn affects the antecedents of engagement, for example, the motivation to sustain academic performance. Finally, Kahu describes the role that motivation plays in engagement, as both intrinsic and instrumental, where the former is characterised by joy and pleasure of an action, and the latter is characterised by what outcomes that action yields. Kahu's framework aligned to critical shifts in the landscape of HE at varying levels at that time [17]. A better understanding these motivations, and the implications of their interplay, is still a significant goal of engagement research.

Formative assessments, much like the curriculum as a whole, are part of the learning process, making them scenarios of student experience where engagement can be observed and potentially affected through the use of classroom-level interventions which 'significantly affect their experiential affordances', such as gamification [13]. Deterding originally defined gamification as the use of video game design elements in non-game contexts (for example, in class lessons or assessments) in order to 'significantly alter' the experiences of an interaction by increasing one's motivation to participate and the enjoyment of participating [1]. A recent mapping study indicates a dramatic rise in year on year publication of primary sources for gamification in education, indicating that this approach is becoming more popular in the classroom [2]. This work shows that empirical studies mostly focus on gamification as it pertains to the classroom level of $\mathrm{HE}$, and consistently show overwhelmingly positive results from students, particularly when gamification promotes rapid feedback, social engagement, visible status, freedom of choice, and freedom to fail [2]. Certain aspects of gamification have been defined, and shown to have repeated positive effects on the attainment of specific learning outcomes across the whole of Bloom's Taxonomy of Learning Domains [14]. This work has been built upon to offer a framework for how gamification intervenes in learning experiences, though not specifically engagement [3], [4].

There is still debate as to how gamification affects engagement in learning as it is theoretically understood. There is also no methodology for gamifying and no standard for what qualifies as effective gamification in or out of education, and thus there is no way of knowing what forms of gamification are more effective or appropriate for application in formative assessment. We have synthesised gamification, engagement, and assessment theories, and present a consolidated Framework for Gamification for Student Engagement for Higher Education (HE). We have devised an accessible, usable process for the gamification of formative assessment which adheres to this theoretical framework. The resulting original teaching and learning enhancements will apply in any university practicing constructivism. Studying the impact of gamification on engagement with formative assessment may provide HE with the means to meet its greatest present and future challenges head on, with potential impact across the sector and beyond.

\section{METHODOLOGY}

In order to synthesise gamification, engagement and assessment theories to form a workable framework to support gamification in practice we looked for literature linking two or more of these concepts together. We found a body of work focused on connecting gaming attributes (defined as the most basic aspects of a game, which can be used to gamify an experience [14]) with training outcomes [4], [14]. 19 distinct game attributes, in nine categories, have been defined, taking the form of concepts such as: control; interaction; fantasy; and levels, which are used to create context and 
agency within a game, or artefacts such as: pieces; leader boards; or points, which represent the changing state of the context and consequence of agency [14]. Bedwell et al. retroactively applied these 19 game attributes to previous research where gamification and serious games were shown to support specific training outcomes, as described in Kraiger and Bedwell's theory of learning [4], [15]. By consolidating the results of these studies, Bedwell formed a taxonomy describing which game attributes support which learning outcomes across the academic literature.

Bedwell's Taxonomy of Game Attributes provides us with a benchmark by which we can compare the achievement of training outcomes defined by Kraiger in gamified formative assessments, and potentially prove or disprove this link between game attributes and learning outcomes through the use of gamified formative assessments [4], [15]. However, the next step in the method required us to recontextualise Bedwell's use of training outcomes into Bloom's Taxonomy of Learning Domains, as this is more commonly used in the design of formative assessment learning outcomes, particularly within the UK context [16]. The recontextualised taxonomy into a tool that can be used to organise and filter game attributes based on intended learning outcomes, and can aid design of gamified formative assessment (Table. 1).

Having linked gamification and assessment theories via learning outcomes, we sought to identify literature that links gamification to engagement. Landers sought to better understand how gaming attributes influenced learning and did this by developing a theory of gamified learning. Gamification was differentiated from the similar concept of Serious Games, where the game is the instructor: '[unlike serious games,] gamification practitioners do not generally seek to influence learning directly; instead, the goal of gamification is to alter a contextual learner behaviours or attitude [...] which is intended to improve pre-existing instruction as a consequence of that behavioural or attitudinal change.' Thus a gamifier who wishes to support learning must know what kinds of changes to what kinds of behaviours and attitudes will help a learner utilise the instructional content in a manner that best supports achievement of the learning content, ideas that can be mapped onto frameworks for engagement which contain elements of behaviour. Additionally, the advent of Bedwell's taxonomy of game attributes allowed Landers to observe that serious games often used game attributes indiscriminately, where gamification instead 'involves the identification, extraction, and application' of game elements such as those featured in Bedwell's Taxonomy, used in 'limited, meaningful combinations'. Landers states that game attributes are applied to the instructional content, but selected independently of instructional content. Instead game attributes are selected based on desired changes to behaviours and attitudes that would best help the student achieve their learning outcomes. This provides Landers with the basis for formulating a theory of gamified learning, based on five propositions focussed on behaviours and attitudes [3]. The link with student engagement comes via Kahu's seminal work which created a multidimensional framework of Student Engagement that also has at its centre behaviours and attitudes [5]. Particularly pertinent to our study is the observation that the psychological perspective of engagement provides a multi-dimensional description of the state of engagement, compring three aspects: emotion, cognition and behaviour [5]. This allows for the state of engagement to be distinguished from its antecedents. We therefore take Lander's work [3] one step further and map onto it Kahu's Framework for Student Engagement [5] to form a new Gamification for Student Engagement framework (Fig. 1).

\section{RESULTS}

We have aligned the training outcomes in Bedwell's Taxonomy of Game Attributes [4] to Bloom's Taxonomy of Learning Domains [16] to make them more accessible in the UK HE context (Table. 1). The majority of training outcomes map onto Bloom's Taxonomy without issue, with the exception of 'application' which may have implications for engagement (not shown). Similarly the game attributes progress/surprise, pieces/ players and location have an undefined relationship with the training outcomes/ taxonomy and so have not been shown in the table. 
Table 1. Bedwell's Game Attributes [4] Mapped onto Bloom's Taxonomy of Learning [16]. After table 4 [4]

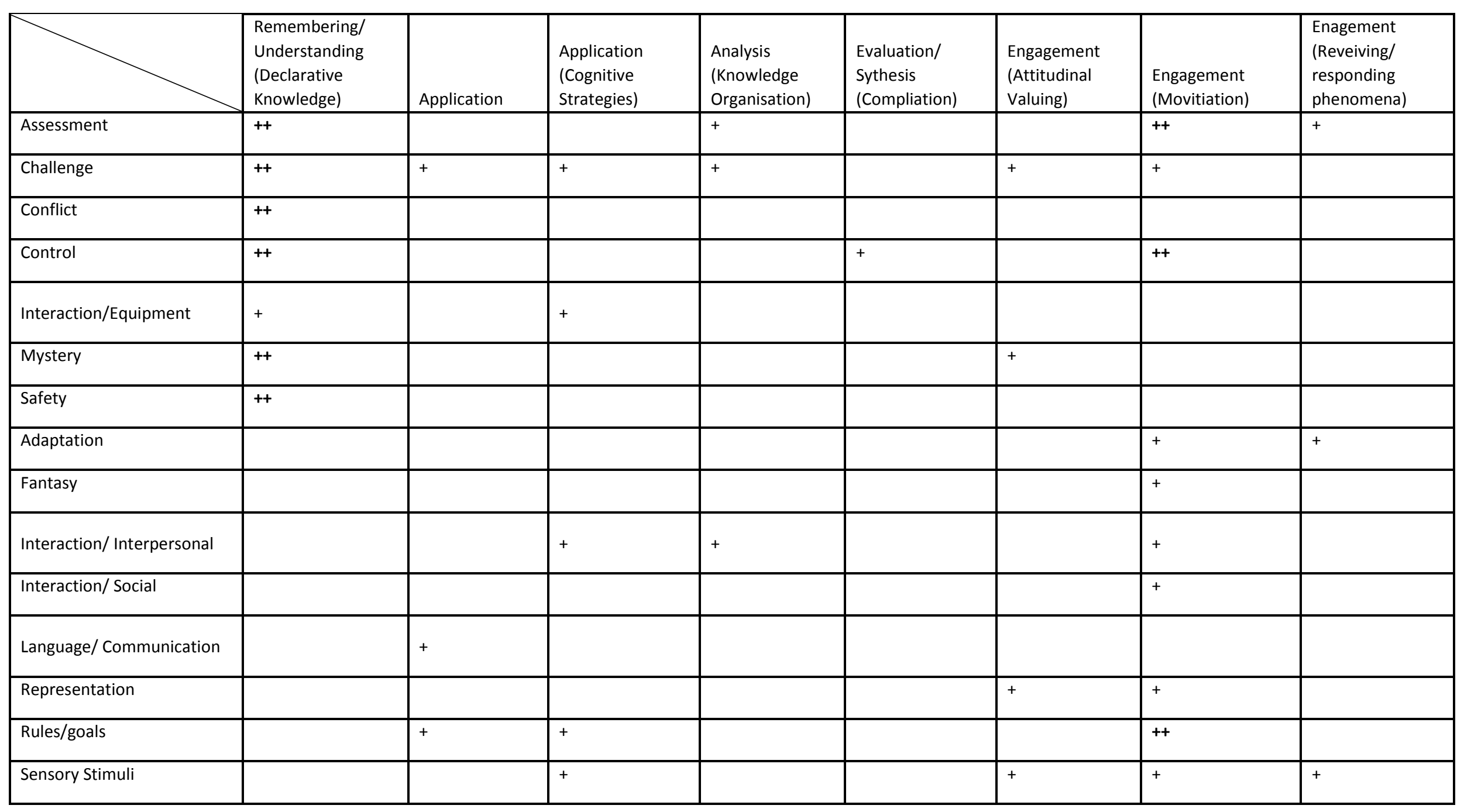


We have mapped and linked theoretical frameworks of gamification, formative assessment, and student engagement in the form of a framework for Gamification for Student Engagement (Fig. 1). Their foundations remain uncompromised and so they remain practically applicable in the design of formative assessment. Landers' gamified learning framework [3] provides the basis of this design, and contextualising in the theory of formative assessment has yielded this study's first major observation. Landers' framework calls for the implementation of game attributes into instructional content to affect students behaviours and attitudes. However, instructional content, or instructional information which facilitates the achievement of learning outcomes, is not a required element of formative assessment design except with regards to the design and delivery of formative feedback. Therefore, we conclude that the gamification of formative assessment requires the implementation of game attributes in the design of formative feedback.

A student's response to formative feedback, as described by Black \& Williams theory of formative assessment [10], is dependent psychological and sociological states, which are characteristic of both Kahu's description of Engagement [5] and Lander's 'Behaviours and Attitudes' [3], making engagement a viable target for the effect of gamified formative feedback. However, Kahu's Engagement framework exists in three parts, where the state of engagement is only one [5]. This state is preceded by the antecedents of engagement, one of which is assessment, which in this case represents Landers' instructional content. The state of engagement is followed by the consequences of engagement, one of which is learning and achievement, which Landers' framework would recognise as the achievement of Kraiger et al.'s training outcomes [15]. The successful alignment of three theoretical frameworks represents the second major observation of this study, and makes feasible the design of a theoretically sound process for gamifying formative assessment as well as the valid measurement of its affects on engagement (Fig. 1).

We also present an iterative 'observe, evaluate, apply' process for gamifying formative assessments with the intent to improve student engagement where each step feeds into the next (Fig. 2, Table 2). 
D.

C.

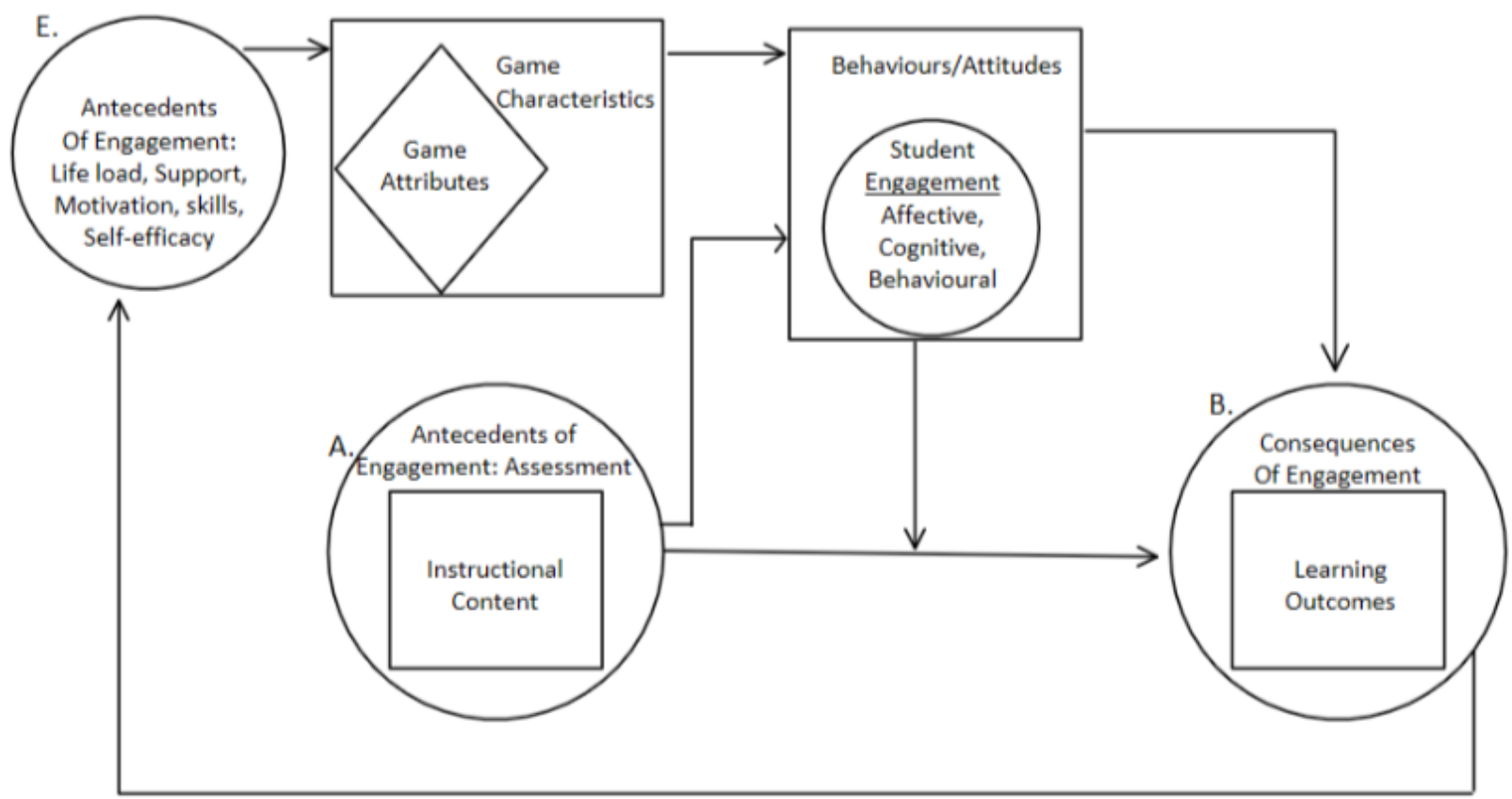

: Landers' Theory of Gamified Learning; A.->C.->B., D.->C.->B.

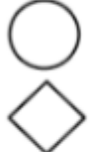

: Kabu's Framework for Student Engagement; A.->C.->B., E.->C.->B., B.->E.

:Bedwell's Taxonomy of Game Attributes; D.->B.

Figure 1. The Gamification for Student Engagement Framework

Relationship between elements of Landers' Theory of Gamified Learning ([3], square), Kahu's Framework for Student Engagement ([5], circle) and Bedwell's Taxonomy of Game Attributes ([4], diamond). Assessment feedback is an antecedent of engagement, which can be likened to the instructional content of a game (A). The student/ player engages with the assessment/ content through behaviours and attitudes (C) to achieve the learning outcome, a consequence of engagement $(B)$. Game characteristics/ attributes $(D)$ influence the behaviour/ attitudes of the student/ player and hence the state of engagement, which is also influenced by the antecedents of engagement (E). Kahu proposes that engagement is circular, where increased engagement leads to increased outcomes of engagement such as academic performance, and in turn affects the antecedents of engagement, for example, the motivation to sustain academic performance $(B, E)$.

Figure 2. The Observe, Evaluate, Apply Iterative Method for Gamifying Formative Assessment

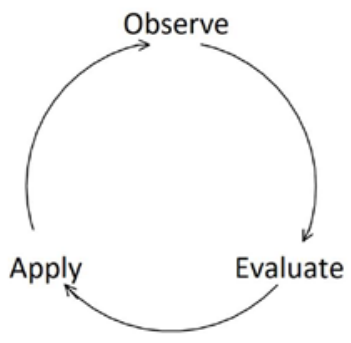

An iterative method of observation, evaluation and application of different parts of our framework for Gamification for Student Engagement as applied in Table 2. 
Table 2. The Iterative 'Observe, Evaluate, Apply' method of gamifying a formative assessment using our framework for Gamification for Student Engagement

\begin{tabular}{|c|c|c|c|}
\hline & Observe... & Evaluate... & Apply... \\
\hline 1. & $\begin{array}{l}\text {-Formative Assessment (FA) } \\
\text {-Module Learning Outcomes (LO) }\end{array}$ & $\begin{array}{l}\text {-LOs covered by Formative Assessment } \\
\text {-Using own experience, identify skills, actions, and } \\
\text { knowledge student must demonstrate to achieve LOs }\end{array}$ & $\begin{array}{l}-3 \text { Domains of learning to write SUB-LOs using the } \\
\text { most appropriate verbs across all three domains } \\
\text { [16]. }\end{array}$ \\
\hline Example 1. & $\begin{array}{l}\text {-FA: Class test linking concepts in a module } \\
\text {-LOs } \\
\text { - LO1: Remember vocabulary \& explain } \\
\text { concepts } \\
\text { LO2: Apply theoretical frameworks to } \\
\text { scenarios } \\
\text { LO3: Design an experimental protocol }\end{array}$ & $\begin{array}{l}\text { - E.g. LO2 } \\
\text {-Requires internalising theories \& connecting concepts }\end{array}$ & $\begin{array}{cl}- \text {-SUB-LOs } \\
- \\
- & \text { LO2 } 1 \text { : Distinguish... } \\
- & \text { LO22: Abstract... } \\
& \text { LO23: Adhere... }\end{array}$ \\
\hline 2. & SUB-LOs & $\begin{array}{l}\text {-Domains of learning for each SUB-LO [16] } \\
\text {-Using experience and student feedback, identify } \\
\text { challenges that each SUB-LO presents to students in } \\
\text { each domain }\end{array}$ & $\begin{array}{l}\text {-Assign SUB-LO to a specific aspect of Student } \\
\text { Engagement from Kahu's Student Engagement } \\
\text { Framework [5] } \\
\text {-Use evidence, experience, or literature to assign } \\
\text { Kahu's Antecedents of Engagement to challenges. } \\
\text { Choose SUB-LO and antecedent thought to impact } \\
\text { most on student engagement. }\end{array}$ \\
\hline Example 2. & LO22: Abstract... & $\begin{array}{l}\text {-Affective, Cognitive, Psychomotor } \\
\text { - Challenges: } \\
\text { - Abstraction } \\
\text { - Internalisation } \\
\text { - Complexity of subject matter } \\
\text { - Foreignness of terms }\end{array}$ & $\begin{array}{l}\text {-Deep Learning } \\
\text { - Antecedents: } \\
\text { - } \quad \text { Motivation }(1,2,3,4) \\
\text { - Identity }(3,4) \\
\text { - } \quad \text { Self-efficacy }(1,3) \\
\text { - } \quad \text { Background }(1,3,4)\end{array}$ \\
\hline 3. & $\begin{array}{l}\text {-Behaviour/Attitudes (BA) } \\
\text {-Antecedents of Engagement (ANTE) }\end{array}$ & -Relationship between $\mathrm{BA}+\mathrm{ANT} \mathrm{T}_{\mathrm{E}}$ & $\begin{array}{l}\text { - Pedagogic theory to explain a function of the } \\
\text { relationship: } B A=f(A N T E) P E D \text { e.g. }[18] \\
\text { Or } \\
\text {-Taxonomy of Game Attributes (GA) to demonstrate } \\
\text { the relationship: } B A=f(A N T E) G A[T a b l e .1,[4]]\end{array}$ \\
\hline
\end{tabular}




\begin{tabular}{|c|c|c|c|}
\hline Example 3. & $\begin{array}{l}\text {-Deep Learning } \\
\text {-Motivation }\end{array}$ & $\begin{array}{l}\text { Focusing on the GA pathway: } \\
\text {-Game Attributes: enabling players to take on difficult } \\
\text { tasks [3], [4] }\end{array}$ & $\begin{array}{l}\text {-Interaction (social) mentors can support players in } \\
\text { greater challenges }\end{array}$ \\
\hline 4. & - FA & $\begin{array}{cl}\text { - } & \text { Break down components of FA ( } \text { CFA }_{\text {FAnto: }} \\
- & \text { Activities } \\
- & \text { Tools/utensils } \\
- & \text { Environment } \\
- & \text { Feedback } \\
- & \text { Rules \& Instructions }\end{array}$ & $\begin{array}{l}\text { - Identify appropriate GAs for each component, } \\
\text { creating a list of GAFAS [4] }\end{array}$ \\
\hline Example 4. & - Class test & $\begin{array}{l}\text { - } \text { Questions \& Answers } \\
\text { - } \text { Pencilents } \\
\text { - Classroom, question sheet } \\
\end{array}$ & $\begin{array}{ll}\text { - } & \text { Challenge } \\
\text { - } & \text { Players } \\
\text { - } & \text { Interaction (equipment) } \\
\text { - } & \text { Location }\end{array}$ \\
\hline 5. & - $C_{F A} \& B A=f\left(A N T_{E}\right) G A$ & 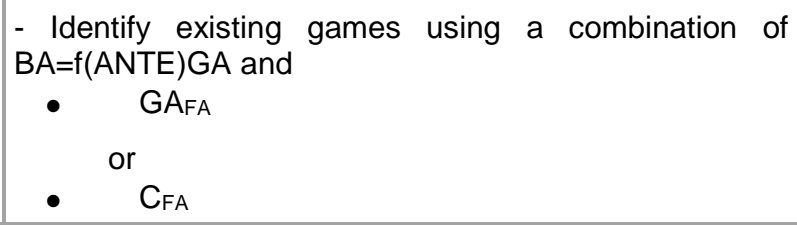 & $\begin{array}{l}\text { Combination from selected game to FA design. } \\
\text { Ideally, feedback should be added, or existing } \\
\text { feedback augmented. }\end{array}$ \\
\hline Example 5. & -Quiz \& Interaction (Social) & $\begin{array}{l}\text {-Dungeons and Dragons } \\
\text {-Charades } \\
\text {-pub quiz }\end{array}$ & $\begin{array}{l}\text { Allowing groups of students to analyse questions in } \\
\text { the social and style of a pub quiz produces } \\
\text { motivation for deep learning through listening, } \\
\text { contributing, and desire to support your team. This } \\
\text { also facilitates peer feedback in the assessment } \\
\text { process where there was none before. }\end{array}$ \\
\hline
\end{tabular}

An iterative process is used to apply The Gamification for Student Engagement Framework to design gamified formative assessment feedback. Each numbered row represents one cycle of the iterative Observe, Evaluate, Apply design cycle, accompanied by a worked example. Cycle 1: the formative assessment and module learning outcomes are observed and the learning outcomes relevant to the formative assessment are evaluated. The practitioner uses their experience to identify what the student must do to achieve these and applies Bloom's Taxonomy of Learning Domains [16] to form sub-learning outcomes. Cycle 2: Practitioners identify challenges for students in each sub-learning outcome which are mapped onto antecedents of engagement, and sub learning outcomes are mapped onto behaviours and attitudes within the engagement framework [5]. Cycle 3: behaviours and attitudes are linked to antecedents identified in cycle 2 using the literature or Bedwell's Taxonomy of Game Attributes [4]. Cycle 4: the formative assessment is broken down into its components and linked to game attributes using Bedwell's Taxonomy [4]. Cycle 5: the outputs of cycle 3 \& 4 are combined with prior knowledge of games resulting in a list of possible games from which to draw the relevant attributes to gamify the formative assessment. 


\section{CONCLUSIONS}

Bedwell's taxonomy, while useful, shows correlation between game attributes training outcomes but not causation [4]. Determining the cause of a game attribute's effect on a particular learning outcome requires 'research on the effects of individual game attributes and features on learning out-comes. Examinations of game attributes will provide evidence for determining what exactly makes a game appropriate for learning' [16]. Now that the relationship between game attributes, learning outcomes, behaviour and engagement is better defined as The Gamification for Student Engagement Framework, we can start to apply this theory in the HE classroom. We intend to use the framework to design experiments that allow us to explore exactly what gamification is affecting in engagement, how this happens, and what to look for to see if its works. This allows us to fill in the blanks between learning outcome and instructional content. We propose the use of a modified TESTA methodology as part of the our approach [7].

\section{ACKNOWLEDGEMENTS}

The authors wish to thank the Edinburgh Napier University Teaching Fellows Development Grant for supporting this work and Dr Samantha Campbell Casey, Dr Kevin Chalmers and Dr Bridget Hanna for co-supervision of ESR's PhD. ESR and CG contributed equally to the work.

\section{REFERENCES}

[1] S. Deterding, M. Sicart, L. Nacke, K. O'Hara, and D. Dixon, "Gamification. using game-design elements in non-gaming contexts," in Proceedings of the 2011 annual conference extended abstracts on Human factors in computing systems - CHI EA '11, 2011, p. 2425.

[2] D. C. G. G. Dicheva, "Gamification in Education: A Systematic Mapping Study.," Educ. Technol. Soc., vol. 18, no. 3, pp. 75-88, 2015.

[3] R. N. Landers, "Developing a Theory of Gamified Learning," Simul. Gaming, vol. 45, no. 6, pp. 752-768, Dec. 2014.

[4] W. L. Bedwell, D. Pavlas, K. Heyne, E. H. Lazzara, and E. Salas, "Toward a Taxonomy Linking Game Attributes to Learning," Simul. Gaming, vol. 43, no. 6, pp. 729-760, Dec. 2012.

[5] E. R. Kahu, "Framing student engagement in higher education," Stud. High. Educ., 2013.

[6] J. B. Biggs, C. S. Tang, and Society for Research into Higher Education., Teaching for quality learning at university: what the student does. McGraw-Hill/Society for Research into Higher Education/Open University Press, 2011.

[7] T. Jessop, Y. El Hakim, and G. Gibbs, "The whole is greater than the sum of its parts: a largescale study of students' learning in response to different programme assessment patterns," Assess. Eval. High. Educ., vol. 39, no. 1, pp. 73-88, Jan. 2014.

[8] C. S. Dweck, Self-theories : their role in motivation, personality, and development. Psychology Press, 1999.

[9] R. Butler, "enhancing and undermining intrinsic motivation: the effects of task-involving and ego-involving evaluation on interest and performance," Br. J. Educ. Psychol., vol. 58, no. 1, pp. 1-14, Feb. 1988.

[10] P. Black and D. Wiliam, "Assessment and Classroom Learning," Assess. Educ. Princ. Policy Pract., vol. 5, no. 1, pp. 7-74, Mar. 1998.

[11] M. Yorke, "Formative assessment in higher education: Moves towards theory and the enhancement of pedagogic practice," High. Educ., vol. 45, no. 4, pp. 477-501, 2003.

[12] C. DeLuca, A. E. A. Chapman-Chin, D. LaPointe-McEwan, and D. A. Klinger, "Student perspectives on assessment for learning," Curric. J., vol. 29, no. 1, pp. 77-94, Jan. 2018.

[13] D. Deterding, S., Khaled, R., Nacke, L.E., Dixon, "Gamification: Toward a Definition," in CHI 2011 Gamification Workshop Proceedings, 2011. 
[14] K. A. Wilson et al., "Relationships Between Game Attributes and Learning Outcomes," Simul. Gaming, vol. 40, no. 2, pp. 217-266, Apr. 2009.

[15] E. Kraiger, Kurt,Ford, J. Kevin,Salas, "Application of cognitive, skill-based, and affective theories of learning outcomes to new methods of training evaluation.," J. Appl. Psychol., vol. 78, no. 2, pp. 311-328, 1993.

[16] D. R. Krathwohl, "A Revision of Bloom's Taxonomy: An Overview," Theory Pract., 2002.

[17] V. Trowler, "Student engagement literature review," York: Higher Education Academy, 2010.

[18] C. Chapman, L. Ramondt, and G. Smiley, "Strong community, deep learning: Exploring the link," Innovations in Education and Teaching International, vol. 42, no. 3. pp. 217-230, 2005. 